\title{
ESTEREOTIPIA: A RELAÇÃO ESTEREOTIPADA PROFISSIONAL/PACIENTE E INIBIÇÃO DO PROCESSO TERAPÉUTICO
}

Teresinha Maria Gonçalves

\begin{abstract}
RESUMO
Neste Relato de Pesquisa a autora trabalha a questão da estereotipia da relação entre profissionais e pacientes no âmbito de uma instituição psiquiátrica. Utiliza como principal suporte, na fundamentação teórica, os aportes de Enrique Pichón RIVIÈRE (1970). A pesquisa foi realizada entre 1981 e 1983 no Paraná e fez parte de sua dissertação de Mestrado defendida em 1989 na Pontifícia Universidade Católica de São Paulo.
\end{abstract}

\section{INTRODUÇÃO}

\section{A CONCEPÇÃO DE SUJEITO}

Para se compreender o sujeito de que Pichón RIVIÈRE fala, temos que colocar os conceitos de verticalidade e de horizontalidade. Verticalidade, para Pichón, se refere à historicidade do

Mestre em Psicologia Social. Professora de Psicologia Social e pesquisadora do Departamento de Psicologia da Universidade Federal do Paraná (1995/1997). Pesquisadora do Núcleo de Pesquisa na Área da Saúde da Universidade do Extremo Sul Catarinense Criciúma - SC. 
indivíduo; a horizontalidade é dada pela sua história social. Este é um dado fundamental. O sujeito que Pichón estudou está neste ponto de intersecção. É só neste ponto de intersecção que se vai encontrar aquele lugar que Pichón chama de "espistemologia convergente".

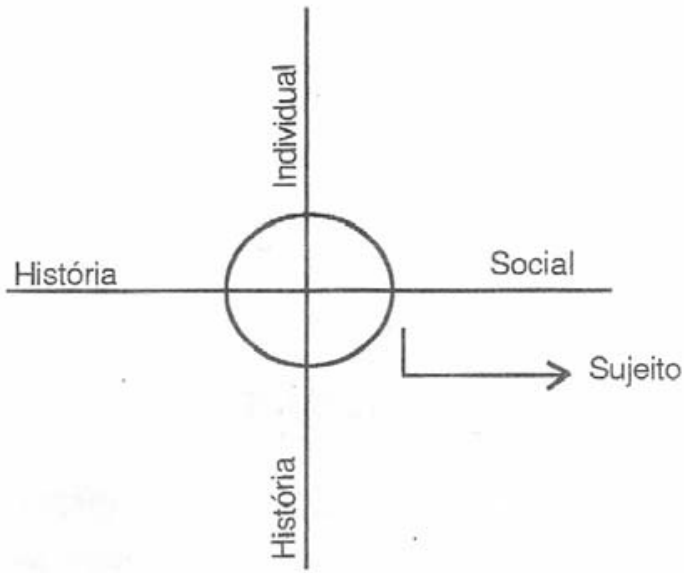

E é só neste lugar que poderá se falar de individualidade do grupo e de sociabilidade do sujeito. É fundamental ressaltar isso, porque aí está todo fundamento da teoria pichoniana a respeito do sujeito e da psiquê. Pichón, utilizando vários caminhos, tendo influências de vários pensadores desde Freud, Melanie Klein, Fairbairn, Bion, Marx, Engels e George Mead, entre outros, sempre procurou demonstrar que o social e o individual pertencem a um lugar comum, que eles conduzem para um mesmo ponto. $\mathrm{O}$ sujeito não é um ser social e um ser individual. Ele é, ao mesmo tempo, social/individual. Sua tese foi no sentido de demonstrar que o social e o individual não caminham lado a lado, não são justapostos, mas estão intrinsicamente interligados. O social está no individual e este no social. É o que Pichón denomina "totalidade totalizante". E este sujeito, do ponto de vista da convergência, é um sujeito que está em interação com outros sujeitos.

Neste momento, Pichón precisa construir um conceito que dê conta da interação social. E o conceito de Pichón para explicar 
a interação social é o conceito de vínculo. Este é um conceitochave na obra de Pichón Rivière.

Posto que a ansiedade é a manifestação da necessidade, o sujeito vai se relacionar com a rede vincular. Nesta rede vincular vão acontecer situações de gratificação e de frustração.

É aqui que Pichón Rivière começa a estruturar o conceito de vínculo. Em vez de um seio bom e um seio mau, Pichón fala de um vínculo bom e um vínculo mau. Não é mais o objeto que é internalizado, mas a relação: nisto consiste a diferença com a visão classicamente adotada pela escola Kleiniana.

Em última análise, a doença mental ou a loucura seriam para Pichón uma patologia da estrutura do vínculo, isto é, uma dificuldade da relação sujeito/objeto ou do sujeito com o mundo. Pichón nunca estuda o indivíduo como ser isolado, mas sim como ser social, incluído dentro de um grupo, basicamente o familiar. Ao mesmo tempo, investiga a inclusão e significação que este grupo tem dentro da sociedade na qual está inserido.

$O$ sujeito se instrumentaliza quando busca a operatividade do vínculo. $\mathrm{E}$, ao buscar a operatividade do vínculo, ele está buscando a adaptação ativa à realidade.

Com a teoria do vínculo, Pichón afasta-se de uma teoria psicanalítica predominantemente intra-psíquica, para formular uma psicologia ou psicologia social que considera o indivíduo não como a resultante dinâmico-mecanicista da ação dos instintos e dos objetos interiorizados, mas sim como resultante do interjogo dialético que se estabelece entre o sujeito e os objetos internos e externos.

Concebe o vínculo como uma estrutura dinâmica. Essa estrutura é constituída pelo sujeito e pelo objeto, que estão em movimento contínuo. A todo momento o vínculo é estabelecido pela totalidade da pessoa, totalidade que Pichón Rivière interpreta como "Gestalt em constante processo de evolução". Tal processo é caracterizado como uma espiral dialética.

Como se vê, Pichón introduz o conceito de vínculo, e substitui a noção de relação de objeto utilizada por Melanie Klein. Afir- 
ma que a noção de vínculo é mais abrangente que a noção de relação de objeto. Um vínculo, para Pichón, pode ser um tipo particular de relação de objeto, já que admite a existência de vários vínculos. Prefere falar em rede vincular, afirmando que a noção de vínculo é mais concreta que a relação de objeto.

Conceitua o vínculo como estrutura.

Coloca RIVIÉRE:

Por que utilizamos o termo vínculo? Na realidade, estamos acostumados a utilizar, na teoria psicanalítica, a noção de relação de objeto, mas a noção de vínculo é muito mais concreta. Relação de objeto é a estrutura interna do vínculo. Um vínculo é então um tipo particular de relação de objeto; a relação de objeto é constituída por uma estrutura que funciona de uma determinada maneira. É uma estrutura dinâmica em contínuo movimento, que funciona acionada ou movida por fatores instintivos e por motivações psicológicas. Diríamos que a noção de relação de objeto é herdeira da psicologia atomística. O vínculo é algo diferente, que inclui a conduta. Podemos definir o vínculo como uma relação particular com o objeto. Esta relação particular tem como conseqüência uma conduta mais ou menos fixa com este objeto, formando um "pattern", uma pauta de conduta que tende a se repetir automaticamente, tanto na relação externa quanto na relação interna com o objeto. Desse modo, temos dois campos psicológicos no vínculo; um interno e outro externo. Sabemos que existem objetos externos e objetos internos. É possível estabelecer um vínculo, uma relação de objeto, com um objeto interno e também com um objeto externo; podemos dizer que aquilo que mais nos interessa do ponto de vista psicossocial é o vínculo externo, enquanto que, do ponto de vista da psiquiatria e da psicanálise, aquilo que mais nos interessa é o vínculo interno, isto é, a forma particular que o eu tende a se relacionar com a imagem de seu objeto colocado dentro do sujeito (1982, p. 37). 
Um ponto importante é a idéia de que o vínculo é estabelecido pela totalidade da pessoa, e não por uma parte da mesma. Pichón afirma que, nesta perspectiva de compreensão, não se pode dizer que o vínculo poderá ser estabelecido por uma parte determinada do aparelho psíquico, como o ld, o Ego ou o Superego. Na compreensão de Pichón, o vínculo se comporta como uma totalidade.

"No vínculo está implicado e complicado tudo."

Com esta afirmação, Pichón dá ênfase à sua concepção de totalidade. A pessoa se move num jogo harmônico ou desarmônico de suas partes integrantes, numa relação de objeto não se pode separar aquilo que é o ld do Ego e do Superego. Em relação à preponderância do Ego, pode-se dizer que o vínculo pode ser mais operacional no sentido de lidar com a realidade, enquanto que, se um vínculo estiver preponderantemente determinado em relação ao superego, será mais carregado de culpa.

Mas, em qualquer das situações, todo o aparelho psíquico está implicado e complicado. Pichón é categórico ao afirmar que não há relação de objeto com uma parte do aparelho psíquico. $O$ aparelho psíquico se comporta como uma totalidade, como uma estrutura dinâmica cujas partes, nesse momento e nesse sujeito, tem valência particular.

Os vínculos internos e externos se integram em um processo que configura uma permanente espiral dialética. Produz-se uma passagem constante daquilo que está dentro para fora, e do que está fora para dentro.

A partir desse enfoque totalizador, Pichón define conduta como "um sistema dialético em permanente interação". Para o entendimento da conduta, introduz o conceito de situação. Define como situação a relação onde ocorrem as modificações sujeito $x$ mundo em que o meio é o agente.

Como conduta define a situação em que a personalidade é o agente. 
A partir de um enfoque totalizador, definimos a conduta como estrutura, como um sistema dialético e significativo em permanente interação, tentando resolver a partir dessa perspectiva as antinomias mente-corpo, indivíduo-sociedade, organismo-meio (Lagache). A inclusão da dialética nos leva a ampliar a definição de conduta, entendendo-a não só como estrutura, mas como instrumento, como unidade múltipla ou sistema de interação, introduzindo-se como conceito de interação dialética a noção de modificação mútua, de inter-relação intrasistêmica (o mundo interno do sujeito) e intersistêmica (relação do mundo interno do sujeito com o mundo externo). Entendemos por relação intra-sistêmica aquela que se dá no âmbito do ego do sujeito, no qual os objetos e os vínculos internalizados configuram com um mundo interno, uma dimensão intra-subjetiva, na qual interatuam para configurar este mundo interno. Este sistema não é fechado, mas por mecanismos de projeção e introjeção relaciona-se com o mundo exterior. A esta forma de relação denominamos intersistêmica. Neste sentido falamos da resolução de antinomias que tem obstaculizado, como situação dilemática, o desenvolvimento da reflexão psicológica no contexto das ciências do homem (RIVIÉRE, 1983, p. 143-144).

Pichón adverte que o vínculo interno condiciona muito dos aspectos externos e visíveis da conduta do indivíduo. Contudo, o que parece importante na teoria do vínculo é que nela se dão os fundamentos para a compreensão de que, ao internalizar um objeto, o indivíduo está internalizando a relação que estabelece com este objeto, e não somente o objeto em si.

\section{Uma teoria da doença/patologia do vínculo}

Quando Pichón faz a análise do vínculo patológico, demonstra o modo pelo qual a estruturação normal da personalidade é perturbada e de que forma deve-se operar sobre o paciente para 
retificar seus vínculos patolágicos, e como se pode contribuir terapêutica e profilaticamente para a evolução sadia da personalidade. Para definir doença mental ou conduta patológica, parte da vertente da psiquiatria na qual se fala de conduta normal e patológica. Inclui, assim, outro par conceitual: saúde $\mathbf{x}$ doença, que define como adaptação ativa ou passiva à realidade. $O$ termo "adaptação" refere-se à adequação ou inadequação, coerência ou incoerência da resposta dada pelo sujeito às exigências do meio, à conexão operativa ou inoperante do sujeito com a realidade. Diz, sobretudo, que os critérios de saúde e de doença, de normalidade e de anormalidade, não são absolutos, situacionais e relativos.

É extremamente importante o postulado básico da teoria da doença de Pichón: toda resposta inadequada, toda conduta "desviada", é a resultante de uma leitura distorcida ou empobrecida da realidade. Ou seja, a doença é uma perturbação do processo de aprendizagem da realidade.

A partir desse ponto de vista, Pichón entende que o sujeito é sadio na medida em que apreende a realidade numa perspectiva integradora, em sucessivas tentativas de totalização. E, modificando essa realidade, ele está conseqüentemente modificando a si mesmo; nesse sentido, está constantemente crescendo, evoluindo.

O sujeito é sadio na medida em que pode manter um interjogo dialético com o meio, e não uma relação passiva, rígida e estereotipada.

A saúde mental consiste, diz Pichón RIVIÉRE, numa aprendizagem da realidade através do enfrentamento, do manejo e da solução integrada dos conflitos; conseqüentemente, a doença é a tentativa fracassada dessa solução. Fracassada porque é tentativa fragmentada, que não sintetiza nem totaliza a situação na qual emergiu o conflito. Afirma que, a partir de um enfoque totalizador, pode-se definir a conduta como estrutura, assim como ele também define o vínculo a partir de uma estrutura. 


\section{Estereotipia}

A Estereotipia se estabelece na relação profissional/paciente quando o vínculo não é visto como estrutura, e não é estabelecido pela totalidade da pessoa. $O$ enquadre do sujeito como paciente contribui para a cristalização da relação como diria GUATTARI (1981), a relação torna-se molar em vez de molecular. A relação se dá através de partes estereotipadas - condutas rígidas frente à tarefa de "cura" motivada pela ativação dos medos básicos frente à situação de mudança. Seria como se repetisse um script na conduta fechada de repetição, sem atividade crítica.

\section{O Ecro}

O Ecro para Pichón RIVIÈRE é um esquema conceitual, referencial e operativo, que serve, ao mesmo tempo, de instrumento e de referência, para que o sujeito ou o grupo operacionalize sua prática. No Ecro, a teoria pauta o repertório metodológico com o qual o sujeito é abordado em suas condições concretas de existência. É uma modalidade de instrumento de trabalho que poderá ser aplicado na investigação científica, na clínica e em outras abordagens da Psicologia Social.

Del ECRO, del esquema conceptual, referencial y operativo planteado en esta Escuela decimos que en tanto es una óptica, en tanto es una modalidad de lectura dialéctica que permite visualizar las contradicciones que se dan en un grupo, de esse ECRO decimos, que se fundamenta en un método de pensamiento, el método dialético, que permite una concepción estructural, una concepción totalizadora de la realidad entendo-a en su carácter de compleja y contradictoria. Este esquema conceptual, referencial y operativo implica el abandono de un pensamiento lineal, dilemático, sometido al clásico principio de no-contradicción, en el que los opuestos sólo se excluejen, es decir, algo no puede se bianco y negro al mismo tiempo, algo no puede ser bueno y 
malo al mismo tiempo, algo no puede ser deseado y temido al mismo tiempo. Es decir que los opuestos desde el pensamiento lógico-formal, se excluyen, y la contradición no es un rasgo de la realidad sino que es una anomalia del pensamiento. Un pensamiento dialiético reconoce la diferencia, la contradicción y relación entre el sujeto y el grupo; pero, justamente, pone su ejemplo en el análogo de su relación: su determinación recíproca. Entonces el sujeto está determinado, está configurado en un processo interacional, pero a su vez el grupo es un sistema de relaciones concretas entre sujetos y no transciende esas relaciones, es decir, no existe una entidad psíquica 'grupo'. Y esto va a traer como consecuencia que nosotros planteemos, por ejemplo, que no existe una fantasia grupal sino un sistema, una estructura de fantasias (QUIROGA, 1979).

\section{A Pensão Protegida}

Segundo ALBUQUERQUE (1978), na Análise Sociológica da loucura na Europa, com o advento do capitalismo mercantil que edigia um "novo homem", muitos trabalhadores ficaram à deriva por não satisfazer as exigências deste "novo homem". Entre eles estavam os loucos que "perturbando a ordem" não satisfaziam a essa nova necessidade social.

Enquanto que na Europa o doente mental passou a ser um problema frente à nova ordem econômica, no Brasil esse processo ainda não havia sido instalado e já era grande a circulação de doentes mentais pelas cidades chamando a atenção das autoridades.

Apesar desse fato sociológico, o Brasil importa da Europa a ideologia da organização da loucura; as idéias referentes aos loucos e as instituições psiquiátricas foram adequadamente "tropicalizadas" aqui no Brasil. 
Na história da Psiquiatria no Brasil, segundo COSTA (1981), até meados do século XIX, os doentes mentais não tinham nenhuma assistência médica. Quando não transitavam pelas ruas eram encarcerados em celas especiais das Santas Casas de Misericórdia.

Na primeira metade do século XX, muitos manicômios foram criados no Brasil. Em 1960 quase todas as capitais brasileiras tinham um manicômio.

Neste contexto, é inaugurado no Paraná, nos arredores de Curitiba (Piraquara) em 1954 o Hospital Psiquiátrico Adauto Botelho.

A Pensão Protegida foi uma experiência realizada no Hospital Colônia Adauto Botelho - H.C.A.B. (1981-1983) no município de Piraquara-PR em uma casa localizada no pátio do hospital. Esta casa abrigou vinte pacientes (mulheres) com alta hospitalar que não tinham para onde ir.

O objetivo da Pensão Protegida era afastar as ex-pacientes do ambiente hospitalar, colocando-as em um ambiente parecido com o que tiveram um dia em suas vidas, isto é, casa, família e trabalho. A finalidade era proporcionar às ex-pacientes, agora pensionistas, a oportunidade de experimentar a "parte sadia" de sua personalidade e assumir seu novo papel.

Este papel seria o de "gente", dado que no hospital sempre assumiram, tão-somente, o papel de paciente numa relação em que eram o objeto do plano de intervenção do médico. Acreditavase que, com este convívio, em um ambiente mais sadio que o hospital, as ex-pacientes pudessem reorganizar suas vidas e até assumir um trabalho com vínculo empregatício e se desligar paulatinamente da Pensão Protegida.

A Pensão Protegida iniciou seu funcionamento sob a coordenação de uma equipe básica formada por um médico, um assistente social, uma psicóloga e uma orientadora. O H.C.A.B. era conhecido, na época, como um hospital asilo e "fim de linha". As pacientes, na grande maioria, internavam-se sozinhas através da 
viatura policial ou através do Pronto Socorro Psiquiátrico de Curitiba, que fazia a triagem e as levava de ambulância até o hospital.

A população escolhida para a experiência da Pensão Protegida fazia parte e tinha as características dessa população asilar do hospital. Eram mulheres que, já antes do internato, haviam visto minguar todo e qualquer vínculo familiar ou afetivo com pessoas significativas, que lhe pudessem alimentar a auto-estima ou reforçar-Ihes a lembrança da força agregadora do amor. Estavam ali mulheres com a personalidade seriamente comprometida; fazendo um vínculo "simbiótico" com a instituição (hospital), não percebiam o seu estado de regressão psíquica, a ponto de esquecer os cuidados básicos quanto à higiene pessoal e postura física.

Os sintomas produtivos, como alucinações e delírios, há muito haviam desaparecido na maioria delas; talvez por isso estavam de alta hospitalar. Convém lembrar que estes são sintomas de uma situação intolerável ao indivíduo e, ao mesmo tempo, seu esforço para a cura. Na visão da equipe da Pensão Protegida, isto se deu devido à ausência de estímulos no projeto terapêutico do hospital e ao uso, às vezes desnecessário, de doses elevadas de neurolépticos. A afetividade das pacientes parecia embarcar num dos vagões do embotamento.

A inauguração da Pensão Protegida deu-se sob grande expectativa quanto ao rumo que tomariam aquelas mulheres, confinadas há anos ou meses em seus pavilhões, desacostumadas a participar ativa e responsavelmente das decisões quanto a seu próprio futuro; desacostumadas a exercer a capacidade laborativa e a experimentar a realidade em seus alcances e limitações. Havia, em alguns médicos da equipe, a fantasia de que ali se instalaria algo parecido com um "bordel" onde predominaria a promiscuidade.

O projeto da Pensão Protegida gerou várias polêmicas; após várias discussões com o corpo clínico, foi aprovado no final do ano de 1981 com o apoio decisivo da Direção Geral. 


\section{METODOLOGIA}

\section{O ECRO como método}

Toda a pessoa, ao se relacionar com os outros, com o mundo e com a sociedade, parte de um esquema próprio, de uma abstração ou visão própria que tem de si, dos outros e do mundo.

O ECRO, conceito criado por Enrique Pichón RIVIÈRE (1970), é um modelo operativo que não se reduz à aprendizagem em grupo; é uma concepção do trabalho grupal. Desta perspectiva poder-se-á enunciar o que Pichón Rivière chama de Esquema Conceitual Referencial e Operativo. É um esquema porque Pichón se situa na perspectiva de uma teoria da aprendizagem na qual é importante determinar certos núcleos de informação e de ação que são fundamentais. Esquema significa aqui conjunto de noções e de conceitos sobre aprendizagem; pode-se entender também esquema como um conjunto articulado de conhecimentos. É conceitual porque faz referência a um grupo de idéias básicas e fundamentais para o trabalho. É referencial porque este esquema de conceitos vai servir de referência - marco de referência em um âmbito onde certas situações podem ocorrer e serem compreendidas pelas pessoas ou pelo grupo.

BRICCHETTO (1974) diz que, em cada situação de aprendizagem, o ECRO serve como ponto de referência a que se recorre para compreender as distintas situações que se dão no nível individual, grupal, institucional ou comunitário, que são as áreas de expressão da conduta.

Este esquema de referência é organizado por conceitos; por um esquema de idéias que alcança uma vasta generalização; são sínteses, mais ou menos gerais, que o sujeito faz do mundo que o cerca. No trabalho científico, é um conjunto de conhecimentos que proporciona linhas de trabalho e investigação. Pichón afirma que a investigação psicológica ou a investigação em outra área do conhecimento, sem um adequado esquema conceitual, seria cega e infrutífera. O importante é salientar que o ECRO passa a ser, a 
partir dessa concepção, um recurso metodológico, um elemento de análise na investigação do campo das Ciências Humanas; mas não é somente no campo da ciência e investigação que o ECRO pode se constituir um elemento metodológico. Existe ECRO para investigar e ECRO para viver o cotidiano. É operativo porque com este esquema se pode trabalhar, se pode operar em aprendizagem individual e em aprendizagem grupal. Portanto, este esquema de referência permite trabalhar no nível do indivíduo, do grupo, das instituições e da comunidade.

Este critério de operatividade é fundamental porque no processo de investigação não interessa somente que a interpretação da realidade ou do fenômeno seja exata, mas fundamentalmente interessa a adequação dessa interpretação em temos de operação, isto é, a possibilidade de promover uma modificação criativa ou adaptativa da realidade. Pichón assinala que entre os elementos fundamentais do ECRO está o conceito de realidade segundo um processo dialético que a cada "a posteriori" de uma situação dada, se converte em "a priori" de uma nova situação, segundo o modelo tese, antítese e síntese. Pichón aproxima sua concepção de método à concepção de método dialético de LOWY (1978).

Afirma RIVIÉRE:

A medida em que se estuda um processo dialético, a relação homem e meio - o ECRO instrumento de aproximação incluirá uma metodologia dialética. A Psicologia Social que postulamos tem por isso um caráter instrumental e não se resolve em um círculo fechado, mas numa contínua realimentação da teoria conceituada por uma crítica e uma autocrítica, realimenta e corrige a teoria mediante mecanismos de retificação (1977, p. 2).

\section{Operacionalização do método}

Da equipe foram entrevistados quatro profissionais; do universo de vinte pacientes foram entrevistadas cinco. O tipo de 
entrevista se configurou como entrevista aberta, onde o tema foi a Pensão Protegida. As entrevistas foram gravadas, transcritas e analisadas à luz da categoria de ECRO.

Definição do objeto de estudo

Neste contexto teórico, o objeto de estudo foi definido como a relação entereotipada do profissional/paciente e inibição do processos terapêutico.

\section{Objetivo da pesquisa}

Analisar a experiência da Pensão Protegida evidenciando as relações estereotipadas entre equipe e pacientes, entre pacientes e hospital e entre equipe e hospital.

\section{DISCUSSÃO E CONCLUSÃO}

\section{A dinâmica da vivência das pacientes e equipe}

A tônica do discurso das pacientes entrevistadas foi a resistência à tarefa da Pensão Protegida, isto é, a tarefa de habitar temporariamente uma casa para tentar refazer sua vida. A Pensão Protegida foi explícita e severamente rechaçada pelas pacientes como coisa ruim, enganosa, que não lhes deu futuro.

O ECRO inicial das pacientes foi marcado por uma preocupação com o trabalho e com o sentir-se explorada. "Trabalhando, trabalhando. Eu já trabalhei em lugar que hoje em dia eu não trabalho de jeito nem que eu não trabalho mais eu não agüento mais. Tô destrampada de serviço. Tô igual animal velho.., eu não agüento mais trabalho. Trabalhar eu trabalhei muito lá trabalhei que aborreci de trabalhar ali sem futuro"1. "Eu quero ir embora não quero ficar aqui"?

\footnotetext{
Entrevista com a paciente M.J.S.

2 Entrevista com a paciente L.R.F.
} 
As pacientes não viram saída para a sua situação, não vislumbraram "futuro". Na realidade concreta, não tinham mesmo para onde ir, não tinham mais família, eram analfabetas ou semianalfabetas e, no caso das pacientes entrevistadas, tinham mais de cinqüenta anos e nenhuma qualificação profissional.

A equipe percebia que no coração das pacientes imperava sobressalto e temor; perderam a antiga casa (hospital) e a "estabilidade". A pensão era concebida, na percepção das pacientes, como uma "aventura" que as colocaria numa sociedade de onde foram expulsas e da qual haviam fugido através da loucura.

As pacientes entrevistadas experimentaram uma vida de muita privação, de muita perda e sofrimento, antes de serem internadas. Viveram vários casamentos, várias separações, perda de filhos. Uns que morreram outros que se "extraviaram pelo mundo". Tiveram uma vida afetiva cheia de violência, sem um vislumbre de prazer. Uma delas se casou aos quinze anos, obrigada "a força", segundo o próprio depoimento. "Menina eu não casei por querer não. Ajuntaram e me casaram. Ajuntaram um bocado de mim e me casaram. Eu sou baiana, quando eu vim do Estado da Bahia eu tinha trinta anos e trouxe três filhos... trouxe uma filharada que não me conhece mais" ${ }^{3}$.

"Não vim por querer, vim pra qui, vim porque um infame me pegou lá de surpresa lá no meu terreiro no meu quartinho onde eu morava e eu ia procurar outros meios, mas ele chegou lá me ponhou no carro que não deu tempo de eu ponhar o chinelo pra calçar. Vim pra qui descalça, não vim desprevenida de roupa porque eu vim de camisola, vim de combinação".

"Quero ir pro Albergue onde nóis tava...".

Esta condição de vida denunciada pela paciente em que se dá o processo do "adoecer', conduz a um alto grau de experi-

\footnotetext{
${ }^{3}$ Entrevista com a paciente M.J.S.

${ }^{4}$ Entrevista com M.J.S.

${ }^{5}$ Entrevista com a paciente L.R.F.
} 
mento de "desamor", de experiência de repetidos fracassos, repetidas perdas, o que leva a um montante de frustrações e de desesperança.

A Pensão Protegida serviu como um estímulo para o tratamento. As pacientes começaram a ter delírios, alucinações, expressar medo e liberar agressão. Na comunidade do hospital, surgiu a idéia de que as pacientes teriam voltado a enlouquecer e que, por isso, a Pensão Protegida não teria dado certo; deveria ser fechada.

$\mathrm{Na}$ maioria das vezes, no meio psiquiátrico e mesmo fora dele, o processo de cura é visto como um processo estático, fechado. Geralmente se pensa que a pessoa se "curou" quando desaparecem os sintomas.

Pichón RIVIÉRE, por sua vez, propõe o projeto de "cura" como um projeto plástico, aberto: estamos permanentemente nos tratando, à medida que estamos refletindo sobre nossas diferenças.

No conteúdo implícito é possível perceber que o "apavorante" para as pacientes era o trabalho de "cura"; o enfrentar a doença. Talvez daí a idéia do "engano" que aparece "camuflada" nos discursos das pacientes. Em vez de ser uma casa de moradia, a Pensão passou a ser um local de tratamento.

A paciente descreve um de seus internamentos o que corresponde exatamente o modo de como muitas pacientes eram internadas há alguns anos atrás. Na época (a paciente estava no hospital há mais de cinco anos), a paciente se descontrolava em casa; a família chamava uma ambulância de Saúde Pública, INAMPS ou a Rádio Patrulha; a paciente era pega quase sempre à força e internada.

Desencadeou um processo terapêutico que era novo e desconhecido tanto para as pacientes quanto para a equipe; e trabaIhar o novo, tentar retomar o caminho até o ponto de estancamento é sempre doloroso.

Nessas circunstâncias, a angústia provocada pelos medos básicos, isto é, o sentimento de perda e o medo do ataque, é 
muito grande. Em relação à Pensão Protegida, os sentimentos persecutórios foram preponderantes. "Vieram tudo contra mim naquela casa e foi indo tomei um ódio da casa, tomei raiva da casa. Não fiquei quieta, não tinha sossego para dormir, era uma vida desassossegada menina, aquele lugar. E lá eu não dormia, virou uma vida de um jeito tudo contra mim que eu não dormia, virou tudo, tudo, te digo com certeza, tudo contra mim"6.

"Eu cheguei aqui, Deus me livre, creio em Deus Padre todo Poderoso, tudo trancado, as privadas não são limpa, tudo podre, tudo fedendo... pode morrer de jogar água... tudo encardido"7.

Em relação ao hospital foi o sentimento de perda. "Foi um espaço que eu dei, saí daqui para ir para a pensão. Pra mim foi perdido aquele espaço".

O tempo todo as pacientes viveram o sentimento de ambivalência; aceitar ou não a pensão; entrar ou não na tarefa de cura. Voltar ao hospital representava o conhecido e, até certo ponto, uma situação mais confortável e segura. A angústia provocada pelos medos básicos foi mais forte, o que impediu o andamento do processo. A cada "martelada na rocha", pacientes e equipe recuavam assustadas com o estrondo e o medo dos "estilhaços".

E o "corpo clínico" do hospital torcendo contra... No conteúdo explícito estava o trabalho pelo qual se sentiam exploradas; mas no conteúdo implícito estava o medo de enfrentar o processo terapêutico, o medo de "remexer" em um "baú" que, de uma forma ou de outra, o "tratamento" do hospital conseguiu acomodar, pois as pacientes estavam de alta.

Todo este quadro se configura como um processo de resistência à mudança, onde não há o enfrentamento dos medos básicos; e a angústia gerada por essa situação impotencializa o sujeito para experimentar o novo, levando-o a recorrer ao uso de

\footnotetext{
6 Entrevista com a paciente M.J.S.

7 Entrevista com a paciente L.P.F.

8 Entrevista com a paciente M.J.S.
} 
pautas estereotipadas que representam o conhecido, o menos assustador, o mais seguro.

As pacientes viram no hospital uma casa segura, onde não precisavam trabalhar. Nem trabalhar para manter a casa, nem trabalhar a loucura, pois o uso de medicamentos era o forte do 'tratamento". E o recorrimento às pautas estereotipadas impede o processo de aprendizagem que proporcionaria nova leitura da realidade e uma adaptação ativa à mesma. As pacientes tinham uma adaptação passiva à realidade do hospital, proporcionada pelo uso de condutas estereotipadas "o médico é quem cura", "preciso de remédio", "o assistente social achará minha família, arrumará uma casa, um emprego".

A Pensão Protegida, na cabeça da equipe, pretendeu ser o caminho em busca de uma perspectiva de vida para as pacientes fora do hospital. Caminho tortuoso, às vezes duro como uma rocha. É difícil imaginar brotar uma flor de uma rocha.

Foi uma tarefa grande demais para a equipe e para as pacientes. A visão do tamanho e do peso da tarefa assustou pacientes e equipe, impotencializado-as; e a equipe, como estava no mesmo processo, não pode ser o continente transferencial necessário nesta fase.

Todo mundo morreu de medo.

O caminho foi percorrido até o final por poucas pessoas. Só algumas pacientes (cinco) conseguiram sair da pensão. Conseguiram se colocar numa vida digna com casa, trabalho, e resgatar alguns vínculos familiares.

O processo dialético não foi posto em ação pela equipe, isto é, a vivência das pessoas na Pensão Protegida não foi vista como um processo dinâmico de "idas" e "vindas", de "altos" e "baixos", de frustração e gratificação, de medo e de coragem.

A equipe não viu como "coisa natural" os momentos difíceis; talvez não teve em que se apoiar para daí "tirar" a coragem para enfrentar esses momentos difíceis. A equipe teve dificuldade de "acreditar" que pudesse haver uma mudança qualitativa tanto na 
conduta das pacientes, como na sua própria. Teve dificuldade para trabalhar as contradições, decorrência natural de toda e qualquer vivência. Como diz Pichón RIVIÉRE, a doença mental se insurge porque as pessoas não têm uma relação dinâmica com o mundo, o que as impede de resolver seus pontos de estancamento. Parece que a equipe teve dificuldade de acreditar nisso. A equipe não soube manejar os momentos de convergência e de divergência. No pensamento dialético, a contradição e a diferença são elementos constitutivos da relação entre os sujeitos e entre estes e o grupo.

"A Pensão fechou por tensões internas, são os mecanismos de defesa que o profissional usa... ele utiliza certos mecanismos de defesa que são úteis para ele mas não para instituição e chega, às vezes, a negar certas possibilidades do paciente"”.

Por outro lado, as pacientes resistiam em sair do papel de "pacientes"; papel' este que Ihes foi outorgado pelo hospital. Respondiam a esta expectativa institucional, isto é, a de "serem cuidadas". E na pensão esperavam que alguém cuidasse delas. Parece que não queriam ser independentes, não acreditavam que poderiam ter uma vida produtiva. Essas pautas estereotipadas inibiram o processo terapêutico.

Alguém, esse "terceiro", que sempre estava presente, era o "outro", que às vezes era percebido como sendo o hospital ou o seu dono, o governo; mas em outros momentos reagiam e queriam trabalhar, sair da pensão. Iam na sala do Diretor solicitar trabalho, coisas para a pensão.

"As pessoas estavam tão bem que saíam do prédio da pensão e iam direto ao prédio da administração forçar uma situação com a Direção do Hospital”"10.

Os sentimentos experimentados pelas pacientes nesta vivência da pensão foram, portanto: sentimento inicial de rechaço

\footnotetext{
9 Entrevista com o médico da Pensão Protegida.

10 Entrevista com o assistente social da Pensão Protegida.
} 
frente à pensão que era o novo e o ameaçador para elas; sentiram-se exploradas pelos trabalhos domésticos e pela equipe que necessitava delas para fazer a experiência da Pensão Protegida; sentimentos de sobressalto e temor frente à ambigüidade da tarefa da Pensão Protegida; reviveram, na pensão, os sentimentos provocados pela vivência de desamor, da "falta de felicidade", da falta do prazer tão constantes em suas vidas pregressas; sentimentos de perda frente ao hospital e sentimentos de medo frente à pensão.

\section{A denúncia do processo}

As pacientes denunciaram as contradições vividas pela equipe na Pensão Protegida. A primeira denúncia foi mostrar que a pensão se estruturou como um hospital. A pensão, que seria uma casa de moradia, se transformou num local de tratamento, na medida em que lá se esboçou um processo terapêutico. A pensão exigiu trabalho, trabalho de fato, mas exigiu, principalmente, trabalho terapêutico, trabalho de "cura".

Mas, para que trabalhar? Lá no hospital não era preciso. No fundo, as pacientes mostraram que o hospital é que era a "pensão", pois moraram lá e foram se "tratar" na pensão. Este foi um grande ensinamento que as pacientes deram à equipe.

A segunda denúncia foi mostrar que a equipe colocou-se em uma situação sem saída. Perceberam que a pensão era uma moradia temporária e se desesperavam por vislumbrar um futuro sombrio fora da pensão, sem família, sem possibilidades concretas de arranjar trabalho, casa e comida. A pensão não foi uma casa para elas; foi, sim, a ameaça concreta e a constatação de que tinham perdido a segurança do hospital. "Não eu não esperava de sair de lá que era pra nóis sair de lá assim. Não esperava arriscado até eles tocar nóis aí pelas estrada pra ir embora. Os que guenta passa o tempo nos tormento. Então eu pedi a elas pra 
me trazer pra cá outra vez assim eu vou embora pra í pro mundo, não tem onde eu vou ficá mesmo eu não vou negá" ${ }^{11}$.

A terceira denúncia foi mostrar o medo e o desespero da equipe. A paciente M.J.S. assim se referiu a um membro da equipe. "Também C. não apareceu mais. Só lá de vez em quando, Deus ajudou ela que assussegou. Porque cada um sabe do que passa é como estou te dizendo. Cada um de nóis todos gosta mais um dos outros, mesmo na hora da aflição cada um sabe o que passa e qual é os que agüenta né"12.

E a pessoa referida pela paciente confirma este medo: "Bem, eu acho que pessoalmente pra mim a Pensão Protegida foi uma experiência dolorosa e um pouco frustrante, talvez devido à minha própria situação pessoal. Na época não consegui, acho que não consegui aproveitar mais da experiência, na época eu acho que não consegui perceber muita coisa que estava acontecendo com as pacientes, que estava acontecendo com a tensão dentro do hospital"13.

A quarta denúncia foi mostrar o papel estereotipado dos membros da equipe. Choravam, desabafavam com a psicóloga; queixavam-se de dores físicas e pediam remédio ao médico e solicitavam emprego, ajuda financeira, documentos e localização da família ao assistente social, "...quero que a senhora fale na assistência social... tenho minhas casinha lá e a assistência social me leva lá". A equipe tinha à sua frente uma paciente dividida entre o psicólogo, o médico e o assistente social. Na Pensão Protegida, o trabalho de grupo pretendeu ser o espaço para as pacientes resgatarem seus vínculos internos e externos. A equipe, contudo, repetiu a experiência do hospital, uma vez que compartimentalizou o conhecimento de cada profissional.

\footnotetext{
11 Entrevista com a paciente M.J.S.

12 Entrevista com a paciente M.J.S.

${ }^{13}$ Entrevista com a psicóloga da Pensão Protegida.
} 
Esta visão compartimentada do conhecimento determinou a prática da Pensão Protegida, na medida em que o médico, o psicólogo e o assistente social fizeram cada um o seu trabalho de grupo separado. As pacientes iam para a reunião de grupo com o médico, para uma outra reunião de grupo com o assistente social e para uma terceira reunião de grupo com a psicóloga. Ainda tinham atendimento individualizado com os três profissionais. Percebe-se então que tanto a equipe, como as pacientes, também se utilizaram das pautas estereotipadas tradicionais na experiência no hospital.

O ECRO das pacientes, da equipe da Pensão e do Hospital

As pacientes, como a equipe, tinham o seu esquema de referência alicerçado nas experiências de suas vidas. O Ecro das pacientes frente à Pensão Protegida foi pautado por uma concepção de "trabalho" e de "exploração". Este conceito não era claro para elas. Ao nível do explícito, o "trabalhar" na pensão era cuidar da casa, lavar roupa, fazer limpeza; e, por esse serviço, esperavam um pagamento em dinheiro. Mas ao nível do implícito, seria o "trabalho de cura".

"...passava a enceradeira em tudo e lavava o corredor e lavava tudo, limpava mesa e tirava caneca e lavava escada e lavava tapete e limpava cozinha..."14.

As pacientes não tinham consciência dos custos da casa. Em sua grande maioria, pertenciam a uma "população flutuante"... que sempre é tratada, na nossa sociedade, como dependentes e é acostumada a receber "favores". Essa população geralmente mora nos albergues do governo, é atendida pela "assistência social" e, quando trabalha, mora nas fazendas ou casas dos patrões.

Para a equipe da Pensão foi como se um "sonho idealizado" não se concretizasse. $O$ Ecro da equipe foi pautado pelos papéis estereotipados de cada profissional, pela concepção de mundo e

14 Entrevista com a paciente M.J.S. 
de sociedade que cada um tinha. A aproximação da realidade através de sínteses sucessivas, característica da concepção dialética, não aconteceu.

Por sua vez, o hospital não fugiu à regra da sociedade. Tratava as pacientes como dependentes suas. Dava-lhes casa, comida, "tratamento". O hospital teve uma função semelhante àquela do "terceiro" de que fala Pichón Rivière, isto é, um elemento existente enquanto pano de fundo neste processo, enquanto experiência anteriormente vivida e, portanto, conhecida tanto para as pacientes quanto para a equipe. Em relação à concepção de tratamento, as pacientes recorreram, em dados momentos, ao ECRO do hospital, isto é, "alguém trata os pacientes"; assim, esperavam que alguém as "tratasse". O processo terapêutico, para as pacientes não era visto como um processo dinâmico onde ela, "a paciente", é que deveria ser o elemento mais ativo. O hospital estava ali a lembrar-Ihes, o tempo todo, de que o conhecido, o velho, é mais confortável, é mais acessível. Então, a volta a pautas estereotipadas foi uma constante. Um passo dado à frente correspondia a dois passos para trás.

O hospital representava o grande papel confuso, a lei ora explícita, ora oculta. Transmitia sempre mensagens veladas, escamoteadas, e as pacientes perceberam isso. "Era uma 'grojetinha' que aparecia lá pra mim... eles faziam as turmas lá e dava, repartia um pagamento, um dinheiro feio, um pagamento lá e eles nunca explicam que pagamento era esse. Eu desconfiava ser alguma coisa meu mas até que morresse"15.

Durante a experiência da Pensão Protegida foram estabelecidos dois movimentos. Um movimento da equipe contrário ao movimento da instituição, um movimento das pacientes, que ora embarcavam no desejo da equipe, ora embarcavam no desejo do hospital, e um movimento contraditório da equipe que retornava ao movimento do hospital nas horas de dificuldade.

15 Entrevista com a paciente L.P.F. p. 165.

Interação, Curitiba, v. 1, p. 153-177, jan./dez. 1997 
O movimento do hospital era manter tudo na inércia. A equipe e pacientes fizeram, em alguns momentos, o movimento de mudança, mas não agüentaram viver esse processo. A hipótese levantada é de que não estariam, pacientes e equipe, preparados para viver esta mudança; não adianta só ter o desejo de mudar, o desejo precisa viabilizar a mudança. Tem que se ter ferramentas para quebrar a "rocha".

As pacientes se perguntavam. "Estou trabalhando para quê? E para quem?".

Não havia similitude de ECRO entre pacientes e equipe em relação à tarefa explícita da Pensão Protegida. E, frente a situações ambíguas, como defesa, voltam as pautas, as condutas estereotipadas.

O fechamento da Pensão Protegida se deu no momento máximo de resistência à mudança. $A$ impossibilidade de realização da tarefa por parte da equipe e das pacientes criou um impasse.

A falta de apoio institucional, não providenciando supervisão à equipe, ao contrário, a instituição manteve uma atitude de cobrança contínua, quase diária, foi fator decisivo para o seu "desmonoramento". Assim, a equipe não agüentou e pediu à Direção do H.C.A.B. que fechasse a Pensão Protegida.

Esta reflexão pretende dar uma contribuição ao trabalho das equipes de Saúde Mental e à prática da Psicologia Social nas instituições.

\section{REFERÊNCIAS BIBLIOGRÁFICAS}

1 ALBUQUERQUE, J. A. Guilhon. Metáforas da desordem. Rio de Janeiro : Paz e Terra, 1978.

2 BARANGER, W. Posição e objeto na obra de Melanie Klein. Porto Alegre : Artes Médicas, 1981.

3 BRICCHETTO, O. Três classes sobre ECRO. Córdoba / Argentina, 1974. Aulas proferidas em la Faculdad de Humanidades de la Universidad de Córdoba, abril/maio 1974. 
4 COSTA, J. E. História da psiquiatria no Brasil. Rio de Janeiro: Campus, 1981.

5 GUATTARI, F. Revolução molecular/pulsações políticas do desejos. São Paulo: Brasiliense, 1981.

6 INSTITUTO PICHÓN RIVIÉRE DE SÃO PAULO. O processo educativo segundo Paulo Freire e Pichón Rivière. Petrópolis: Vozes, 1987.

7 KLEIN, M. Textos escolhidos. São Paulo : Ática, [19- -] (Coleção de Grandes Cientistas Sociais, n. 32).

8 LOWY, M. Método dialético e teoria política. 2. ed. Rio de Janeiro : Paz e Terra, 1978.

9 QUIROGA, A. P. Aulas proteridas na Primeira Escuela Privada de Psicologia Social, fundada por Enrique Pichón Rivière. Nos dias: 8, 13, 15, 20, 22 e 27 de maio de 1979.

10 _. Psicologia social y ECRO. Aulas proferidas na Primeira Escuela Privada de Psicologia Social, fundada por Enrique Pichón Rivière. Buenos Aires/Argentina: 24 de abril de 1979.

11 QUIROGA, A. P. La conceptión del sujeto en el pensamiento de Enrique Pichón Riviàre. Buenos Aires/Argentina. Revista de Psicanálise, n. 3, 1978.

12 RIVIÈRE, E. P. O conceito de ECRO, aula n. 2 do 1 ano do curso de 1970 na Primeira Escuela Privada de Psicologia Social. Buenos Aires/Argentina. (Texto traduzido por Marco Aurélio Fernadez Velloso).

13 . O processo grupal. São Paulo Martins Fontes, 1983.

14 Teoria do vínculo. São Paulo : Martins Fontes, 1982. 